\title{
Solution to the isotope dilution challenge
}

\author{
Enea Pagliano
}

(C) Her Majesty the Queen in Right of Canada 2014

The joint winners of the isotope dilution challenge (published in volume 406, issue 22) are:

Beatrice Campanella and Lorenza Biancalana, University of Pisa, Italy, and Jeremy E. Melanson, NRCC, Ottawa, Canada

The award entitles the winning groups to select a Springer book of their choice up to a value of $€ 100,-$.

Our Congratulations!

\section{Solution}

Over the years, isotope dilution mass spectrometry (IDMS) has witnessed many reformulations. One of the earliest expressions for this quantitation model was given by the single isotope dilution (ID ${ }^{1} \mathrm{MS}$ ). In $\mathrm{ID}^{1} \mathrm{MS}$, the mass fraction of an analyte $\mathrm{A}$ is obtained from mass spectrometric analysis of a mixture (blend) of sample and an isotopically-enriched form of the analyte (B) which acts as an internal standard:

$w_{A}=w_{B} \times \frac{m_{B(A B)}}{m_{A(A B)}} \times \frac{R_{B}-R_{A B}}{R_{A B}-R_{A}} \times \frac{\sum R_{A}}{\sum R_{B}} \times \frac{M_{A}}{M_{B}}$

This model requires that the mass fraction of the isotopic standard $\left(w_{\mathrm{B}}\right)$, the isotopic composition of natural $\left(R_{\mathrm{A}}\right)$ and enriched $\left(R_{\mathrm{B}}\right)$ material, and their respective molar masses $\left(M_{\mathrm{A}}\right.$ and $M_{\mathrm{B}}$ ) are known beforehand. It is possible, however, to

This article is the solution to the Analytical Challenge to be found at http://dx.doi.org/10.1007/s00216-014-7977-3

E. Pagliano $(\square)$

National Research Council of Canada, 1200 Montreal Road, Ottawa, ON K1A 0R6, Canada

e-mail: enea.pagliano@nrc-cnrc.gc.ca

E. Pagliano

e-mail: e.pagliano@libero.it design an experiment in order to bypass the prior knowledge of these quantities. For example, in addition to the blend of sample and isotopic standard (AB), one can prepare and measure three additional blends of a primary standard (with natural isotopic composition) and isotopic standard. These blends are denoted $\mathrm{A} * \mathrm{~B}-1, \mathrm{~A} * \mathrm{~B}-2, \mathrm{~A} * \mathrm{~B}-3$, and the following system of four equations now describes the experiment, assuming $R_{\mathrm{A}}=R_{\mathrm{A}} *$ and $M_{\mathrm{A}}=M_{\mathrm{A}} *$ :

$$
\begin{aligned}
& \left(w_{\mathrm{A}}=w_{\mathrm{B}} \cdot \frac{m_{\mathrm{B}(\mathrm{AB})}}{m_{\mathrm{A}(\mathrm{AB})}} \cdot \frac{R_{\mathrm{B}}-R_{\mathrm{AB}}}{R_{\mathrm{AB}}-R_{\mathrm{A}}} \cdot \frac{\sum R_{\mathrm{A}}}{\sum R_{\mathrm{B}}} \cdot \frac{M_{\mathrm{A}}}{M_{\mathrm{B}}}\right. \\
& \left\{\begin{array}{l}
w_{\mathrm{A} *}=w_{\mathrm{B}} \cdot \frac{m_{\mathrm{B}(\mathrm{A} * \mathrm{~B}-1)}}{m_{\mathrm{A}(\mathrm{A} * \mathrm{~B}-1)}} \cdot \frac{R_{\mathrm{B}}-R_{\mathrm{A} * \mathrm{~B}-1}}{R_{\mathrm{A} * \mathrm{~B}-1}-R_{\mathrm{A}}} \cdot \frac{\sum R_{\mathrm{A}}}{\sum R_{\mathrm{B}}} \cdot \frac{M_{\mathrm{A}}}{M_{\mathrm{B}}} \\
w_{\mathrm{A} *}=w_{\mathrm{B}} \cdot \frac{m_{\mathrm{B}(\mathrm{A} * \mathrm{~B}-2)}}{m_{\mathrm{A}(\mathrm{A} * \mathrm{~B}-2)}} \cdot \frac{R_{\mathrm{B}}-R_{\mathrm{A} * \mathrm{~B}-2}}{R_{\mathrm{A} * \mathrm{~B}-2}-R_{\mathrm{A}}} \cdot \frac{\sum R_{\mathrm{A}}}{\sum R_{\mathrm{B}}} \cdot \frac{M_{\mathrm{A}}}{M_{\mathrm{B}}} \\
w_{\mathrm{A} *}=w_{\mathrm{B}} \cdot \frac{m_{\mathrm{B}(\mathrm{A} * \mathrm{~B}-3)}}{m_{\mathrm{A}(\mathrm{A} * \mathrm{~B}-3)}} \cdot \frac{R_{\mathrm{B}}-R_{\mathrm{A} * \mathrm{~B}-3}}{R_{\mathrm{A} * \mathrm{~B}-3}-R_{\mathrm{A}}} \cdot \frac{\sum R_{\mathrm{A}}}{\sum R_{\mathrm{B}}} \cdot \frac{M_{\mathrm{A}}}{M_{\mathrm{B}}}
\end{array}\right.
\end{aligned}
$$

Equation 2 can be solved for $w_{\mathrm{A}}$ to yield:

$w_{\mathrm{A}}=-w_{\mathrm{A} *} \cdot \frac{m_{2} \cdot m_{3} \cdot R_{4}+m_{1} \cdot m_{3} \cdot R_{5}+m_{1} \cdot m_{2} \cdot R_{6}}{m_{1} \cdot R_{4}+m_{2} \cdot R_{5}+m_{3} \cdot R_{6}} \cdot \frac{m_{\mathrm{B}(\mathrm{AB})}}{m_{\mathrm{A}(\mathrm{AB})}}$

where

$m_{i}=\frac{m_{\mathrm{A} *(\mathrm{~A} * \mathrm{~B}-i)}}{m_{\mathrm{B}(\mathrm{A} * \mathrm{~B}-i)}}$

and

$$
\begin{aligned}
& R_{4}=\left(R_{\mathrm{AB}}-R_{\mathrm{A} * \mathrm{~B}-1}\right) \cdot\left(R_{\mathrm{A} * \mathrm{~B}-2}-R_{\mathrm{A} * \mathrm{~B}-3}\right) \\
& R_{5}=\left(R_{\mathrm{AB}}-R_{\mathrm{A} * \mathrm{~B}-2}\right) \cdot\left(R_{\mathrm{A} * \mathrm{~B}-3}-R_{\mathrm{A} * \mathrm{~B}-1}\right) \\
& R_{6}=\left(R_{\mathrm{AB}}-R_{\mathrm{A} * \mathrm{~B}-3}\right) \cdot\left(R_{\mathrm{A} * \mathrm{~B}-1}-R_{\mathrm{A} * \mathrm{~B}-2}\right)
\end{aligned}
$$


Table 1 Symbols and quantities

\section{Symbol Description}

\begin{tabular}{|c|c|}
\hline A & Analyte in the sample (natural isotopic composition) \\
\hline$A^{*}$ & Analyte in the primary standard (natural isotopic composition) \\
\hline $\mathrm{B}$ & $\begin{array}{l}\text { Analyte in the isotopic standard (isotopically enriched } \\
\text { composition) }\end{array}$ \\
\hline $\mathrm{AB}$ & Blend of sample (A) and isotopic standard (B) \\
\hline $\mathrm{A} * \mathrm{~B}$ & Blend of primary standard $\left(\mathrm{A}^{*}\right)$ and isotopic standard $(\mathrm{B})$ \\
\hline$M_{\mathrm{X}}$ & Molar mass of $\mathrm{X}\left(\mathrm{X}=\mathrm{A}, \mathrm{A}^{*}\right.$, or $\left.\mathrm{B}\right)$ \\
\hline$w_{\mathrm{X}}$ & Mass fraction of $\mathrm{X}$ in the aqueous solution $\left(\mathrm{X}=\mathrm{A}, \mathrm{A}^{*}\right.$, or $\left.\mathrm{B}\right)$ \\
\hline$m_{\mathrm{X}(\mathrm{XY})}$ & $\begin{array}{l}\text { Mass of the aqueous solution of } X \text { used to prepare the blend of } \\
X \text { and } Y\left(X, Y=A, A^{*} \text {, or } B\right)\end{array}$ \\
\hline$R_{\mathrm{X}}$ & Isotope amount ratio corresponding to material $\mathrm{X}$ \\
\hline$\Sigma R_{\mathrm{X}}$ & Sum of all isotope amount ratios of the same denominator \\
\hline
\end{tabular}

Equation 3 is known as quadruple isotope dilution (ID ${ }^{4} \mathrm{MS}$ ) [1-3] and it involves only the gravimetric data regarding the four blends along with their isotopic composition. Note that the variables $w_{\mathrm{B}}, R_{\mathrm{B}}$, and $R_{\mathrm{A}}$ have been eliminated in Eq. 3 (Table 1).

The possibility of choosing the isotopic composition of the three calibration blends offers the options for more sophisticated experimental designs for high-precision measurements. In this vein, for best results, the analyst

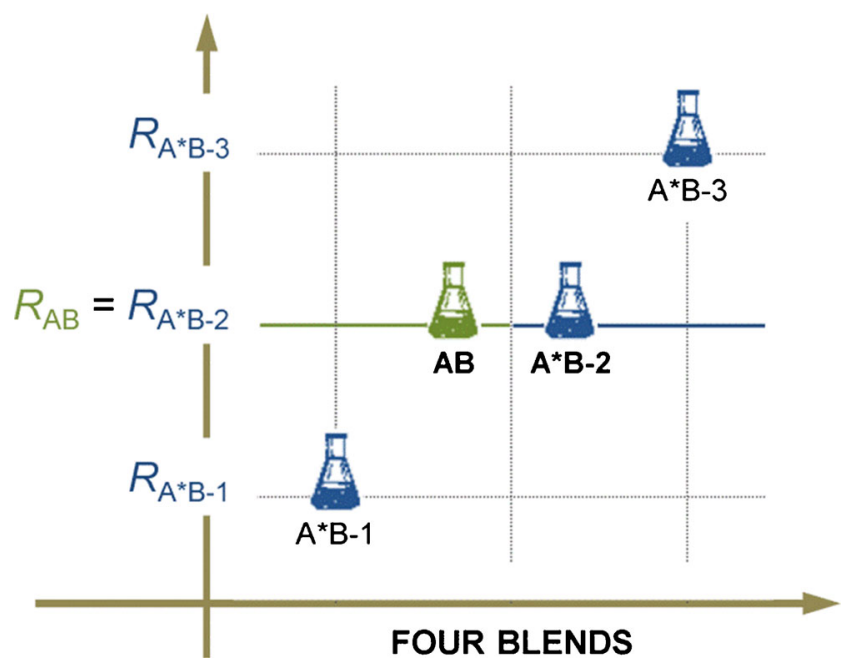

Fig. 1 Exact-matching quadruple isotope dilution. The isotopic ratio of the sample blend $(\mathrm{AB})$ is matched to one of the standard blends $(\mathrm{A} * \mathrm{~B}-2)$, whereas the remaining two standard blends $(\mathrm{A} * \mathrm{~B}-1$ and $\mathrm{A} * \mathrm{~B}-3)$ are chosen to bracket this isotope ratio

might prepare one of the $A * B$ blends to match the isotopic composition of the sample blend (AB) while the other two $\mathrm{A}^{*} \mathrm{~B}$ blends bracket the isotopic composition of $\mathrm{AB}$, as shown in Fig. 1. The data reported in Table 2 reflect such experimental design and can be used to calculate the mass fraction of bromide in the sample of groundwater by using Eq. 3:

$$
\begin{aligned}
& m_{1}=\frac{1.02652}{0.05992}=17.13 \\
& m_{2}=\frac{2.00312}{0.06013}=33.31 \\
& m_{3}=\frac{4.10538}{0.05989}=68.55 \\
& R_{4}=(4.226-6.143)(4.215-2.764)=-2.7816 \\
& R_{5}=(4.226-4.215)(2.764-6.143)=-0.0372 \\
& R_{6}=(4.226-2.764)(6.143-4.215)=2.8187 \\
& w_{\mathrm{A}}=-97.44 \frac{33.31 \cdot 68.55 \cdot(-2.7816)+17.13 \cdot 68.55 \cdot(-0.0372)+17.13 \cdot 33.31 \cdot 2.8187}{17.13 \cdot(-2.7816)+33.31 \cdot(-0.0372)+68.55 \cdot 2.8187} \cdot \frac{06002}{2.00811}
\end{aligned}
$$

from which we obtain $w_{\mathrm{A}}=96.59 \mathrm{ng} / \mathrm{g}$ of bromide. 
Table 2 Experimental data

\begin{tabular}{llllll}
\hline Sample, X & $m_{\mathrm{A}} / \mathrm{g}$ & $w_{\mathrm{A}} /(\mathrm{ng} / \mathrm{g})$ & $m_{\mathrm{A} *} / \mathrm{g}$ & $m_{\mathrm{B}} / \mathrm{g}$ & $R_{\mathrm{X}} /(\mathrm{V} / \mathrm{V})$ \\
\hline $\mathrm{A}\left(\right.$ and $\left.\mathrm{A}^{*}\right)$ & $\mathrm{n} / \mathrm{a}$ & $\mathrm{n} / \mathrm{a}$ & $\mathrm{n} / \mathrm{a}$ & $\mathrm{n} / \mathrm{a}$ & 1.018 \\
$\mathrm{~B}$ & $\mathrm{n} / \mathrm{a}$ & $\mathrm{n} / \mathrm{a}$ & $\mathrm{n} / \mathrm{a}$ & $\mathrm{n} / \mathrm{a}$ & 15.81 \\
$\mathrm{AB}$ & 2.00811 & $\mathrm{n} / \mathrm{a}$ & $\mathrm{n} / \mathrm{a}$ & 0.06002 & 4.226 \\
$\mathrm{~A}^{*} \mathrm{~B}-1$ & $\mathrm{n} / \mathrm{a}$ & 97.44 & 1.02652 & 0.05992 & 6.143 \\
$\mathrm{~A}^{*} \mathrm{~B}-2$ & $\mathrm{n} / \mathrm{a}$ & 97.44 & 2.00312 & 0.06013 & 4.215 \\
$\mathrm{~A}^{*} \mathrm{~B}-3$ & $\mathrm{n} / \mathrm{a}$ & 97.44 & 4.10538 & 0.05989 & 2.764 \\
\hline
\end{tabular}

Alternatively, one can construct a graph in order to derive the value of $w_{\mathrm{A}}$. For this, one plots the ratios $w_{\mathrm{A}}\left(m_{\mathrm{A}} / m_{\mathrm{B}}\right)$ on the abscissa for the three blends $\mathrm{A} * \mathrm{~B}-$ 1 , $\mathrm{A}^{*} \mathrm{~B}-2$, and $\mathrm{A} * \mathrm{~B}-3$, and the corresponding isotope ratios $\left(R_{\mathrm{AB}}\right.$ or $\left.1 / R_{\mathrm{AB}}\right)$ on the ordinate (Fig. 2). Then, the data points are fitted with a suitable function, and the value corresponding to the ratio $R_{\mathrm{AB}}$ is then extrapolated. This corresponds to $w_{\mathrm{A}} \cdot m_{\mathrm{A}} / m_{\mathrm{B}}$ which, in turn, yields $w_{\mathrm{A}}$.

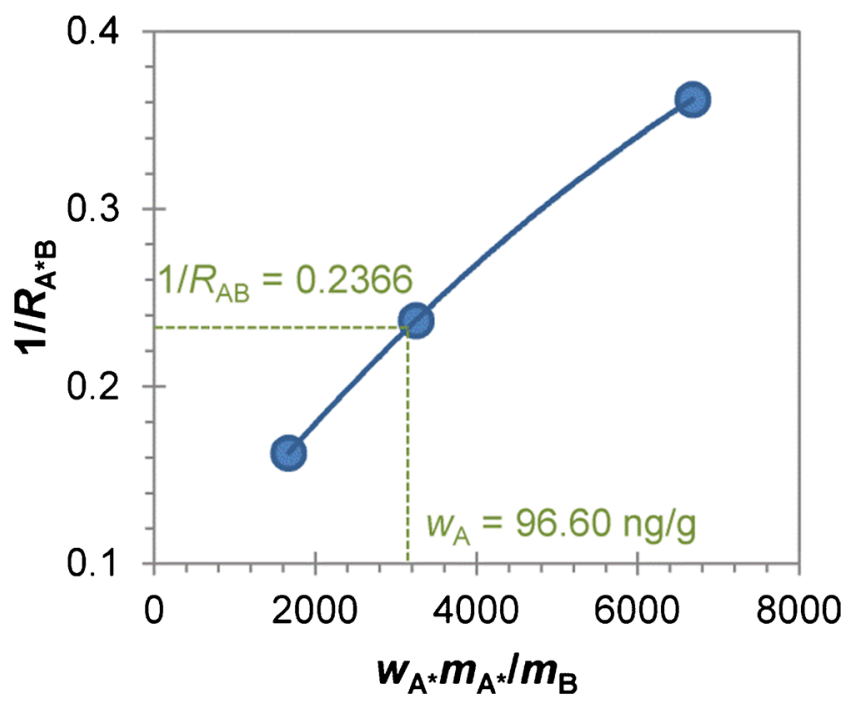

Fig. 2 Graphical solution of the isotope dilution challenge using a nonlinear fitting

\section{References}

1. Pagliano E (2014) Anal Bioanal Chem 406:5249-5250

2. Pagliano E, Mester Z, Meija J (2013) Anal Bioanal Chem 405:28792887

3. Pagliano E, Meija J, Mester Z (2014) Anal Chim Acta 824:36-41 